\title{
Tectonic Activity In The Ganga Plain Foreland Basin During Quaternary
}

\author{
Indra Bir Singh \\ Geology Department, Lucknow University, Lucknow-226007, INDIA
}

Indo-Gangetic Plains, the largest active foreland basin of the Himalaya, developed on an old, cold and rigid Indian lithosphere showing high variability in the down-flexing characteristics. The Ganga Plain making the central part of this foreland basin system shows a diverse fluvial landscape of Late Quaternary age with a variety of fluvial systems. The fluvial geomorphic features often exhibit tectonic control and evidences of active tectonics. Thicknesses of the alluvial fill in the Ganga Plain show control of basement highs. Pattern and orientation of tectonics varies from Himalayan orogen to the Craton margin in the form of compressional tectonics to extensional tectonics respectively. The Craton margin exhibits prominent tectonic movements manifested in the form of vertical uplift, kilometer-scale warping, tilting of blocks, conjugate fractures and gravity faults.
A tectonic event, dated 8-5 kyrs disrupted number of drainages, converting channels into linear lakes; and produced an undulatory topography showing kilometre scale warping. The present-day active rivers show strong control of tectonics in the form of distorted channel segments, uneven height of cliffs along the valley margin. There are distinct zones of more intense tectonics in the form of warping. Often warping is very pronounced along the river channels. The southern part of the Ganga Plain shows several well-defined belts of intense and closely-spaced warping. Tectonic lineaments are mostly well-defined; at few places evidence of faulting is also present. The active tectonics of Holocene in the Ganga Plain has strongly controlled the regional patterns of fluvial facies and sediment transfer. The relationship between tectonic features of the Ganga Plain to the Himalayan tectonics and response of basement are not yet properly understood. 